\title{
Oral immunization of mice using transgenic tomato fruit expressing VP1 protein from enterovirus 71
}

\author{
Hsuan-Fu Chen ${ }^{\mathrm{a}, \mathrm{b}}$, Meng-Huei Chang ${ }^{\mathrm{a}}$, Bor-Luen Chiang ${ }^{\mathrm{b}, *}$, Shih-Tong Jeng ${ }^{\mathrm{a}, *}$ \\ a Institute of Plant Biology and Department of Life Science, National Taiwan University, Taipei, Taiwan, ROC \\ ${ }^{\mathrm{b}}$ Graduate Institute of Clinical Medicine, National Taiwan University Hospital, Taipei, Taiwan, ROC
}

Received 31 May 2005; received in revised form 7 December 2005; accepted 7 December 2005

Available online 17 January 2006

\begin{abstract}
Enterovirus 71 (EV71) causes seasonal epidemics of hand-foot-and-mouth disease associated with fatal neurological complications in young children, and several major outbreaks have occurred recently. This study developed an effective antiviral agent by transforming the gene for VP1 protein, a previously defined epitope and also a coat protein of EV71, into tomato plant. VP1 protein was first fused with sorting signals to enable it to be retained in the endoplasmic reticulum of tomato plant, and its expression level increased to $27 \mu \mathrm{g} / \mathrm{g}$ of fresh tomato fruit. Transgenic tomato fruit expressing VP1 protein was then used as an oral vaccine, and the development of VP1-specific fecal IgA and serum IgG were observed in BALB/c mice. Additionally, serum from mice fed transgenic tomato could neutralize the infection of EV71 to rhabdomyosarcoma cells, indicating that tomato fruit expressing VP1 was successful in orally immunizing mice. Moreover, the proliferation of spleen cells from orally immunized mice was stimulated by VP1 protein, and provided further evidence of both humoral and cellular immunity. Results of this study not only demonstrate the feasibility of using transgenic tomato as an oral vaccine to generate protective immunity in mice against EV71, but also suggest the probability of enterovirus vaccine development.
\end{abstract}

(C) 2005 Elsevier Ltd. All rights reserved.

Keywords: Oral immunization; Transgenic tomato fruit; Enterovirus 71

\section{Introduction}

Oral vaccination is safe and easily administered, making it particularly suitable for protecting against infectious agents intruding bodies via the mucosal surface [1], such as pathogens that cause enteric, respiratory, or sexually transmitted diseases [2]. To date, many microbial antigens expressed in plants have been successfully used for oral immunization in mammals [3-7].

A frequent cause of hand-foot-and-mouth disease is associated with central nerve system disorder and cardiopulmonary collapse since it was first reported in 1969. Enterovirus 71 (EV71) currently has a nearly $80 \%$ fatality rate amongst children in Taiwan [8]. Although several investigations have examined the feasibility of developing a useful vac-

\footnotetext{
* Corresponding authors.

E-mail address: stjeng@ntu.edu.tw (S.-T. Jeng).
}

cine for enterovirus [9-11], no vaccine for EV71 infection has become commercially available. EV71 is an RNA virus with a capsid that comprises four coat proteins, VP1-VP4. VP1 protein has been defined as the neutralization determinant, and can be used to make a subunit vaccine [12]. Moreover, plasmid with VP1 gene by intramuscular injection and VP1 recombinant protein with adjuvant by intraperitoneal injection were both capable of inducing immune response [13]. As a similar disease affecting meat- and milk-producing domestic animals, foot-and-mouse-disease virus (FMDV) also has its critical epitopes in structural protein VP1. Mice immunized with transformed leaf plant extract containing FMDV VP1 elicited specific antibody response, and all of the immunized mice were protected against challenge with virulent FMDV [14].

In considering oral delivery as an alternative antiviral strategy, the first challenge is to achieve a high yield of antigen that is sufficient to provide effective protection. Since the level of 
foreign protein expressed in transgenic plants could be as low as $0.01 \%$, and rarely exceeded $0.40 \%$ of total soluble proteins [15], stable plant transformation and enhancement of protein yielding were the main considerations when producing edible vaccines from plants [16]. The protein sorting signals from plant systems can be used to increase the expression efficiency of recombinant antigen in plant tissues. An endoplasmic reticulum (ER) retention signal was fused to foreign proteins, which accumulated in ER and reached a high yield to increase the efficiency of expression of recombinant antigen in plants [17-19]. Proteins that lacked specific sorting determinants had been proved to follow a default pathway and were consequently secreted toward the surface of the cell [20]; furthermore the addition of the amino acids, NTPP, directed proteins into the vacuoles in plant cells [21].

Plants can be grown in massive quantities easily and cheaply, and tomato fruit can be eaten without heat treatment, which may destroy the immunogenicity of antigen. Therefore, transgenic tomatoes were designed to produce oral vaccines against EV71. In this study, VP1 gene was fused with ER retention signals, and transgenic tomato expressing VP1 protein was created. The capability of fruit-derived VP1 antigen to evoke mucosal and systemic antibody responses in mice was also analyzed. Additionally, the efficiency of EV71 neutralization in mammalian cell culture was examined to evaluate the oral immunogenicity of VP1 protein produced in transgenic tomato.

\section{Materials and methods}

\subsection{Construction of vector expressing VP1 gene}

VP1 gene from pET28a-VP1 (kindly provided by Dr. LiMin Huang) was first fused downstream to the CaMV 35S promoter of plasmid pBI221SI [22], and then signal peptides were inserted into vector to cause VP-1 protein produced by plant cell to accumulate within the endoplasmic reticulum (ER) (Fig. 1). Plasmid pER-VP1 expressing VP1 was created by first inserting the VP1 gene from pET28a-VP1 amplified by polymerase chain reaction (PCR) with the DNA primers VP1-F (AAG GAT CCG GAG ATA GGG TGG CA) and VP1-R-KDEL (AAC CTA GGC TAA TCG AGT AGA AAG AGA GTG GTG ATT GC) into the Bam HI and Avr II sites of pBI221SI. A nucleotide sequence coding for the hexapeptide Ser-Glu-Lys-Asp-Glu-Leu (SEKDEL) for pro- tein retention in ER was then produced by DNA primer VP1$\mathrm{R}-\mathrm{KDEL}$, and was included within pER-VP1. To complete pER-VP1, a 105 bp double strand DNA, named AMVSP, containing a translational enhancer from the alfalfa mosaic virus [23] and the signal peptide from the sweet potato sporamin gene [24], was generated from the ligation of DNA oligonucleotides AMVSP-1F (CTA GAG TTT TTA TTT TTA ATT T), AMVSP-1R (GAA AGA AAA TTA AAA ATA AAA ACT), AMVSP-2F (TCT TTC AAA TAC TTC CAC CAT GAA AGC C), AMVSP-2R (TGT GAG GGC TTT CAT GGT GGA AGT ATT T), AMVSP-3F (CTC ACA CTG GCA CTC TTC TTA GCC CTT T), AMVSP-3R (AGA GGG AAA GGG CTA AGA AGA GTG CCA G), AMVSP-4F (CCC TCT ATC TCC TCC CCA ATC CCG CCG) and AMVSP4R (AT CCG GCG GGA TTG GGG AGG AGA T), and was introduced into the $\mathrm{Xba}$ I and Bam HI positions of pER-VP1 (Fig. 1).

\subsection{Tomato transformation and production}

Plasmid pER-VP1 was mobilized into A. tumefaciens LBA4404 by electroporation. Tomato (Lycopersicon esculentum Mill. Cv. A4) was transformed using the modified seedling methods described below. One-week-old seedlings were excised, cut into $1 \mathrm{~cm}$ lengths with a razor blade, and cocultivated with Agrobacterium in MSG medium (1X MS salts, Gamborg's B5 vitamins $(1 \mathrm{mg} / \mathrm{L}$ thiamine, $0.5 \mathrm{mg} / \mathrm{L}$ nicotinic acid, $0.5 \mathrm{mg} / \mathrm{L}$ pyridoxine, $100 \mathrm{mg} / \mathrm{L}$ myo-inositol), $3 \%$ sucrose, $\mathrm{pH}$ 5.8) for an hour. Explants were then transferred to SL medium (1X MS salts, Gamborg's B5 vitamins, $1 \mathrm{mg} / \mathrm{L}$ BAP, $0.2 \mathrm{mg} / \mathrm{L}$ IAA, $3 \%$ sucrose, $0.8 \%$ agar, $\mathrm{pH} 5.8$ ) with $100 \mathrm{mg} / \mathrm{L}$ kanamycin and $300 \mathrm{mg} / \mathrm{L}$ timetin for transgenic shoot screening. Isolated kanamycin-resistant transformants were subsequently analyzed via PCR for the presence of VP1 gene within the genome, and also by Western blotting to determine the existence of VP1 protein in tomato leaves. Finally, rooted plants were acclimatized and transferred into greenhouses for fruiting.

\subsection{Analysis of transgenic tomato fruits}

Tomato fruits were extracted in $200 \mathrm{mM}$ Tris (pH 8.0), $100 \mathrm{mM} \mathrm{NaCl}$ and $10 \mathrm{mM}$ EDTA. Tissue homogenate was centrifuged at $4{ }^{\circ} \mathrm{C}, 12,000 \mathrm{rpm}$ for $5 \mathrm{~min}$, and the supernatant was gathered and transferred to a fresh tube. Concentration of total soluble protein was estimated using the method of Brad-

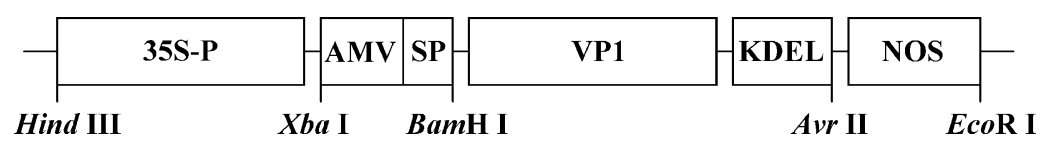

Fig. 1. Schematic representation of the DNA region encoding the VP1 fusion protein used in this study. DNA regions encoding the VP1 in the binary vectors used for Agrobacterium-mediated transformation are displayed. Transcription was driven by the cauliflower mosaic virus $35 \mathrm{~S}$ promoter (35S-P), and ended at the termination region (NOS) from the nopaline synthase gene. AMV is the untranslated leader region from the coat protein of alfalfa mosaic virus, and was used to enhance the translation. The signal peptide (SP) from the sporamin gene of sweet potato and the ER retention signal (KDEL) were fused to VP1, and then VP1 was allowed to retain in ER. 
ford [25]. After calculation, $100 \mu \mathrm{g}$ of the total soluble protein was added with SDS gel loading buffer $(60 \mathrm{mM}$ Tris- $\mathrm{HCl}$ (pH 6.8), 2\% SDS, $10 \%$ glycerol, $0.025 \%$ bromophenol blue and $5 \% \beta$-mercaptoethanol), boiled for $5 \mathrm{~min}$, and subjected to each well of $12 \%$ sodium dodecyl sulfate polyacrylamide gel electrophoresis (SDS-PAGE). Proteins on gel were transferred to a nitrocellulose membrane, blocked using PBST (phosphate-buffered saline (PBS) and 0.5\% Tween-20) containing 10\% dry milk (PBSTM) overnight, and washed twice before incubation with the primary antibody diluted 1:20,000 in PBSTM for $1 \mathrm{~h}$. The membrane was briefly rinsed in PBST following a $15 \mathrm{~min}$ wash and $2 \times 10 \mathrm{~min}$ washes, and then incubated in a 1:2000 dilution of an anti-rabbit IgG conjugated with horseradish peroxidase (Jackson ImmunoResearch Laboratories, Inc.) for $1 \mathrm{~h}$. Finally, the membrane was washed again in PBST, and detected using an Amersham ECL+ kit according to the instructions of the manufacturer. Protein quantification was performed by using NIH Image (available at: http://rsb.info.nih.gov/nih-image/) to compare the detected signals.

\subsection{Immunization of mice}

Female BALB/c mice (6-8 weeks old) were obtained from the Animal Laboratory, Institute of Biomedical Sciences, Academia Sinica, Taipei, Taiwan. Each experimental group comprised six animals. To evaluate immunogenicity, each mouse in group $\mathrm{B}$ was given $6 \mathrm{~g}$ transgenic tomato fruit, and consumed 3-5 g fruit, which contained about 60-80 $\mu \mathrm{g}$ VP1, in $5 \mathrm{~h}$ on days $0,7,14,21$ and 51 . Group $\mathrm{C}$ mice were individually gavaged with $60 \mu \mathrm{g}$ VP1 protein purified from $E$. coli to provide a positive control. Moreover, Group A mice, which provided a negative control, were also fed $6 \mathrm{~g}$ untransformed tomato fruit, and ate $3-5 \mathrm{~g}$ tomato fruit within $5 \mathrm{~h}$. Sera were collected from the eyeholes on days 12, 27 and 56. Fresh feces pellets (about $0.2 \mathrm{~g}$ ) were gathered on days $0,7,14,21,51$ and 56 , and immediately frozen at $-70^{\circ} \mathrm{C}$. Before analysis, the feces pellets were dissolved in $500 \mu \mathrm{l}$ of protease inhibitor solution $(0.01 \%$ sodium azide and $1 \mathrm{mM}$ EDTA, in $1 \times$ PBS) for ELISA assay.

\subsection{Antibody determination in serum and feces by ELISA}

ELISA plates were coated overnight at $4{ }^{\circ} \mathrm{C}$ with $2 \mu \mathrm{g} / \mathrm{ml}$ of bacterial purified VP1 dissolved in carbonate coating buffer ( $15 \mathrm{mM} \mathrm{Na}_{2} \mathrm{CO}_{3}, 35 \mathrm{mM} \mathrm{NaHCO}_{3}$, pH 9.6). Following incubation with $1 \%$ bovine serum albumin (BSA) in PBS for $2 \mathrm{~h}$ at room temperature to prevent non-specific binding, serial dilutions of test sera were added to each well and incubated overnight at $4{ }^{\circ} \mathrm{C}$. Following washing with PBST, bound proteins were detected using horseradish peroxidaseconjugated anti-mouse IgG or IgA (1:90,000; Mouse IgG ELISA Quantitation Kit, E90-131; Mouse IgA ELISA Quantitation Kit, E90-103; Bethyl Laboratories, Inc.). As a substrate, $100 \mu \mathrm{l}$ TMB (KPL, MD, USA) was used, and the reaction was stopped by $50 \mu \mathrm{l} 2 \mathrm{~N} \mathrm{H}_{2} \mathrm{SO}_{4}$. Absorbance was measured at $450-550 \mathrm{~nm}$. The concentration for $\operatorname{IgG}$ and $\operatorname{IgA}$ is indicated as E.U., and one E.U. of IgG and $\operatorname{IgA}$ is 1.78 and $2.04 \mathrm{ng} / \mathrm{ml}$ serum, respectively. Statistical analysis was conducted using the Student's two-tailed $t$-test, and differences between groups with $P$-values below 0.05 were considered significant.

\subsection{RD cell based EV71 neutralization assay}

Rhabdomyosarcoma cells (RD cells) were grown in Dulbecco's Modified Eagle's Medium (DMEM) supplemented with $10 \%$ Fetal calf serum (FCS) at $37^{\circ} \mathrm{C}$. Different concentrations of EV71 required for cytopathic effect (CPE) were served as standards by adding 100 tissue culture infectivity doses (TCID), 10 TCID, 1 TCID or 0.1 TCLD to the RD cell monolayers. The changes in cell death were scored as $+1,+2$, +3 or +4 , corresponding roughly to $<25 \%, 25-50 \%, 50-75 \%$ or $>75 \%$ cells with CPE, and scores exceeding +3 were considered non-protective. The relative efficacy of virus neutralization of anti-sera was assayed by co-incubating $50 \mu \mathrm{l}$ of two-fold dilutions of pooled sera from immunized mice with $50 \mu \mathrm{l} 100 \mathrm{TCID}$ viruses for $2 \mathrm{~h}$ at $37^{\circ} \mathrm{C}$. Subsequently, $100 \mu \mathrm{l}$ of $8 \times 10^{4} / \mathrm{ml} \mathrm{RD}$ cells were added to each well and co-incubated for about $72 \mathrm{~h}$, and recording was started when half of the wells of 1 TCID standards displayed CPE, and no wells of 0.1 TCID standards appeared CPE.

\subsection{Splenocyte proliferation assay and cytokine production}

To determine whether VP1-specific proliferative responses were induced in immunized mice, spleens were removed to make single-cell suspensions 2 weeks after the final booster. Splenocyte proliferation was performed by adding $100 \mu \mathrm{l}$ of $3 \times 10^{6} / \mathrm{ml}$ splenocytes in AIM-V ${ }^{\circledR}$ medium (serum-free lymphocyte medium) with $2 \%$ mouse serum replacement (TCM) to each well in 96-well flatbottom plates. Stimulated wells received bacterial purified VP1 at concentrations of 10,5 , or $2.5 \mu \mathrm{g} / \mathrm{ml}$. A mixture of $\alpha$-CD3 and $\alpha$-CD28 $(1 \mu \mathrm{g} / \mathrm{ml}$, ImmunoTech) provided a positive control, while the negative control wells received cells only. Following three days in culture, the cells were pulsed with $\left[{ }^{3} \mathrm{H}\right]$ thymidine $(1 \mu \mathrm{Ci} /$ well $)$ for $18 \mathrm{~h}$, and harvested with FilterMate (Packard). The incorporated radioactivity was determined using TopCount (Packard). Splenocyte proliferation was considered significant if the stimulation index (S.I., the ratio of how much radioactivity is present in cells from a culture which included the antigen, versus cells in a control culture which was treated the same except that the antigen was not added) was greater than 3 .

In order to measure cytokine secretion, splenocytes were cultured as described above, except that after 48 or $96 \mathrm{~h}$ in culture, cell-free supernatants were harvested and assayed. Supernatants were then screened for the presence of IFN- $\gamma$, IL-5, and TGF- $\beta$ using sandwich-ELISA detection systems 
according to the instructions of the manufacturer (Duoset ELISA Development System, R\&D Systems Inc., MN, USA).

\section{Results and discussion}

\subsection{VP1 gene construction and plant expression}

To allow VP1 protein expression in tomato, the construction of the VP1 gene in vector was modified. The DNA encoding sporamin propeptide from sweet potato was inserted into the $5^{\prime}$ end of the VP1 gene, and enabled fusion protein to enter the ER [24]. The oligonucleotide encoding the ER retention signal (SEKDEL) was further fused to the $3^{\prime}$ end of the VP1 gene, and helped VP1 protein to retain in ER (Fig. 1).

Kanamycin-resistant tomato plantlets were generated after transforming tomato by agrobacteria bearing plasmid pER-VP1 and pVAC-VP1 (Fig. 1). Sixteen pER-VP1 transformed transgenic lines and nine pVac-VP1 transformed transgenic lines were identified by tissue culture. Afterwards, the quality and quantity of VP1 protein was determined via Western blotting using bacterial recombinant VP1 as a standard (Fig. 2A). As the bacterial reference standard VP1 contains ribosomal binding site and T7 tag, its molecular weight appears larger. Two protein species, 35 and $36 \mathrm{KDa}$, from leaves of transgenic tomato were recognized by polyclonal antibody specific to VP1 protein. Being absent from wild-type tomato (A4 in Fig. 2A), both 35 and $36 \mathrm{KDa}$ protein species were considered to be VP1 protein. We found transgenic tomato produced various amounts of VP1 protein
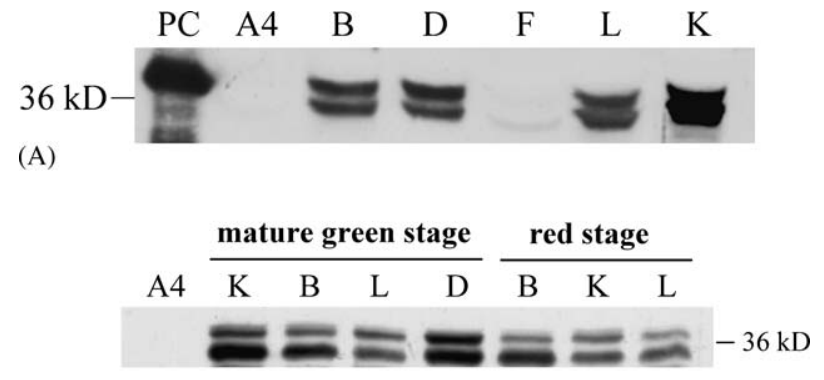

(B)

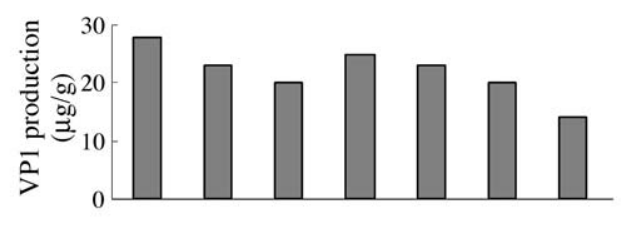

Fig. 2. Expression level of the VP1 protein in transgenic tomato. The amount of loaded total protein extracted from tomato tissue in each well was $100 \mu \mathrm{g}$. The amount of loaded bacterial recombinant VP1 was $10 \mu \mathrm{g}$. (A) Western blot analysis of VP1 protein from the leaves of transgenic tomato. (B) Western blot analysis of VP1 protein expression levels in transgenic tomato fruit. The VP1 protein production is represented as VP1 protein/fresh weight of tomato fruit $(\mu \mathrm{g} / \mathrm{g})$. PC: bacterial VP1 as a positive control; A4: untransformed tomato as a negative control; B, D, F, K and L: transgenic transformation lines which expressed VP1 protein at different levels.
(Fig. 2A), and four of the transgenic lines from pER-VP1 transforments, $\mathrm{B}, \mathrm{D}, \mathrm{K}$ and $\mathrm{L}$, which produced relatively more VP1 protein than other $\mathrm{pVac}-\mathrm{VP} 1$ transforments, were further planted in a greenhouse for fruiting. Following fruit harvesting, Western blotting was performed again, indicating that VP1 protein could accumulate up to $27 \mu \mathrm{g} / \mathrm{g}$ fruit fresh weight, which was high enough for oral immunization assays (Fig. 2B).

When Western blotting analysis was performed, two species of VP1 protein from tomato leaves were observed compared to that of bacterial VP1 protein (Fig. 2A), suggesting the addition of signal peptides in VP1 may cause protein processing of the VP1. Processing may include cutting of signal peptides when protein was transported into organelles [26], and thus two different molecular weights of VP1 antigens existed. Tomato fruit in both mature green stage and red stage also contain these two protein species. These results may indicate that the processing of VP1 protein in tomato is not tissue specific. Again, since these two protein species were recognized by antibody specific for VP1 protein, they were thereby considered to be functional antigens for oral immunization.

\subsection{Mice immunization and induction of serum and mucosal anti-VP1 antibodies}

Six to eight-week-old female BALB/c mice were used in this study. Each group contained six mice, and the groups were given transgenic tomato in red stage (group B), wildtype tomato fruit in red stage as a negative control (group A), and VP1 protein purified from E. coli as a positive control (group C), on days $0,7,14,21$ and 51 (final booster). Each mouse in groups A and B were given $6 \mathrm{~g}$ of sliced, non-peeled tomato fruit, from which the placental tissue and seeds were removed to ensure that the mice were fed only with tomato pulp. For each feeding, without being injected intraperitoneally, mice were allowed to eat tomato by themselves. Within $5 \mathrm{~h}, 3-5 \mathrm{~g}$ transgenic tomato containing approximately $60-80 \mu \mathrm{g}$ VP1 protein were consumed by each group B mouse, while each group A mouse could also eat 3-5 g wild-type tomato fruit as negative controls. Meanwhile, the group C mice were gavaged with $60 \mu \mathrm{g} \mathrm{VP1}$ protein purified from E. coli to provide positive controls.

Systemic and mucosal VP1-specific antibody in sera and feces from immunized mice were then determined by ELISA analysis. The group B and C mice, which were fed transgenic tomato and bacterial VP1 protein, respectively, displayed apparent VP1-specific IgG response that was over twice that observed in the serum from control mice in group A (Fig. 3). Significant $(P<0.05)$ anti-VP1 IgA in feces was also observed (Fig. 4). Furthermore, the memory immunoglobulin B cells were formed in the mice orally immunized with VP1 protein because the strongest IgG and IgA responses at day 56 were found after the final booster (Figs. 3 and 4). These results demonstrated that tomato-derived VP1 protein was successful in oral immunization of mice. 


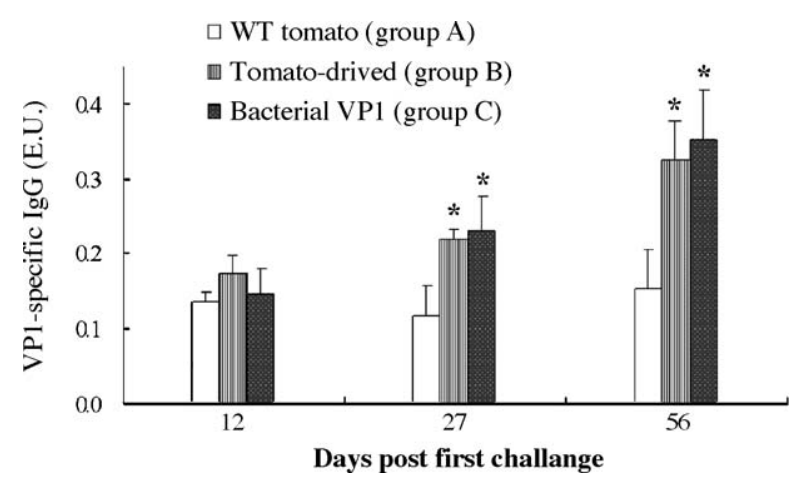

Fig. 3. ELISA detection of IgG antibody induced by VP1 protein. The mice were bled on days 12, 27 and 56. Serum samples were diluted to $100 \times$ in this assay. The concentration of IgG is indicated as E.U., and one E.U. is equal to $1.78 \mathrm{ng} / \mathrm{mL}$ serum. The results were expressed as mean \pm SEM. Statistically significant values $(P<0.05)$ are indicated by an asterisk.

Since the quantity of tomato pulp that mice ate could not be controlled, group B mice might consume more tomatoderived VP1 protein than the bacteria-derived $60 \mathrm{~g}$ VP1 protein fed to group $\mathrm{C}$ mice. However, the data from ELISA assays showed that group $\mathrm{C}$ mice produced slightly more VP1-specific antibodies than group B mice in both sera and feces, indicating that mice chewing and digestion caused degradation of VP1 antigen. Consequently, the method of administration must be considered when performing oral immunization.

Unlike hepatitis B surface antigen, which has been expressed in potato plant and accumulated as virus-like particles (VLP) in membrane-bound vesicles [2], VP1 in EV71 is unable to form particles alone because EV71 has a capsid consisting of four proteins, VP1-VP4 [10]. As it is unlikely to transform all of the coat proteins into tomato plant, finding the way to produce as much VP1 as possible is so far the main aim in generating plant-based oral vaccine.

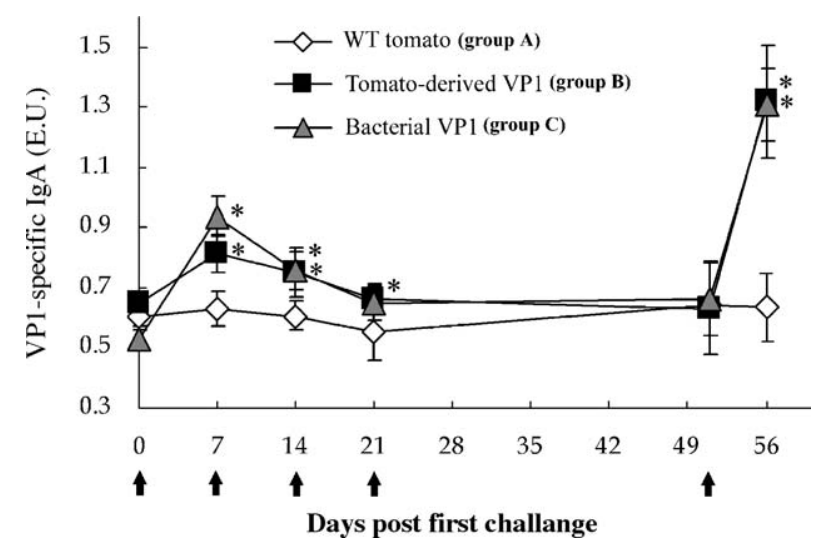

Fig. 4. ELISA analysis of IgA antibody stimulated by VP1 protein. Fresh feces pellets (about $0.2 \mathrm{~g}$ ) were collected on days $0,7,14,21,51$ and 56, and immediately frozen at $-70^{\circ} \mathrm{C}$. Feces pellets were dissolved in $500 \mathrm{ml}$ of protease inhibitor solution before analysis. The concentration of IgA is indicated as E.U., and one E.U. is equal to $2.04 \mathrm{ng} / \mathrm{ml}$ serum. Arrowheads indicate the time of immunization. Statistically significant values $(P<0.05)$ are indicated by an asterisk.

\subsection{Neutralization of EV71 by serum from immunized mice}

Sera from immunized mice were investigated to determine their ability to inhibit EV71 infection in rhabdomyosarcoma (RD) cells. The neutralization assay was performed by coincubating RD cells with diluted serum before EV71 infection. Compared to normal spindle-like RD cells, infected cells appeared swollen with microbodies and eventually released the viruses. The neutralization titer was defined as the highest serum dilution providing over $50 \%$ cell protection against EV71. Pre-immunized serum and serum from mice fed wildtype tomato (group A) displayed no neutralization effect against EV71. Nevertheless, mice orally immunized four times following a final booster with transgenic tomato or bacterial VP1 protein both developed a titer of 1:16 for neutralization protection. Meanwhile, serum from human patients serving as a positive control showed the highest titer of 1:128. Therefore, serum from mice administered with VP1 protein from either $E$. coli or transgenic tomato could neutralize the infectivity of EV71 in vitro.

These in vitro data indicated that serum from mice immunized with tomato-derived VP1 protein had the same neutralizing effect as that of mice immunized using bacterial VP1 protein. However, sera from mice that were fed VP1 antigen, produced by tomato plant or E. coli, remained less effective in neutralization of EV71 than sera from human patients in vitro. For this examination, although it is suggested that both mucosal and serum IgA antibodies could be induced after oral immunization [28], fecal antibody was not used to perform neutralization assay due to the difficulty of collection of large amount of feces for this kind of assay. It is interesting to find out the ability to neutralize EV71 for IgG and IgA, respectively, in the future investigation. In the mean time, to isolate individual isotype from the limited sample that could be obtained remains difficult in this study. Using protection against lethal viral challenge in newborn mice is another means of demonstrating whether oral delivery of tomato leaf VP1 protein is sufficient to provide in vivo neutralization of EV71 [28]. Wu et al. tested the inoculation of EV71 to newborn ICR mice, and found that protection against lethal EV71 infection was achieved from immunized dams [13]. Since the contradiction between in vivo protection and in vitro neutralization provided by antibody has been observed in other viral infections [29], in vivo investigation would provide more information about our vaccine strategy.

\subsection{Splenocyte proliferation}

Splenocyte proliferation is an important indicator for the existence of both humoral and cellular immunity [13]. Spleens were removed two weeks after the final booster to produce single-cell suspensions. Then, spleen cells from each mouse were isolated and stimulated using $2.5,5$ or $10 \mu \mathrm{g} / \mathrm{ml}$ VP1 protein purified from $E$. coli in vitro. POS, a composite 
Table 1

VP1-specific splenocyte proliferation

\begin{tabular}{lllll}
\hline Group $^{\mathrm{a}}$ & \multicolumn{3}{l}{ Splenocyte stimulation index with stimulant } \\
\cline { 2 - 4 } & \multicolumn{3}{l}{} & \multicolumn{2}{l}{ POS $^{\mathrm{b}}$} \\
\cline { 2 - 4 } & $10 \mu \mathrm{g} / \mathrm{ml}$ & $5 \mu \mathrm{g} / \mathrm{ml}$ & $2.5 \mu \mathrm{g} / \mathrm{ml}$ & \\
\hline $\mathrm{A}$ & $2.79 \pm 1.11$ & $2.46 \pm 0.99$ & $1.81 \pm 0.66$ & $66.31 \pm 16.00$ \\
$\mathrm{~B}$ & $6.77 \pm 2.11$ & $7.18 \pm 4.30$ & $3.43 \pm 2.62$ & $65.46 \pm 64.02$ \\
$\mathrm{C}$ & $6.50 \pm 1.53$ & $5.57 \pm 1.81$ & $3.55 \pm 1.32$ & $75.24 \pm 38.31$ \\
\hline
\end{tabular}

${ }^{\text {a }}$ Mice were fed 3-5g transgenic tomato fruit which contain about 60-80 $\mu \mathrm{g} / \mathrm{g}$ VP1 protein (group B), untransformed tomato fruit served as negative control (group A), and $60 \mu \mathrm{g}$ recombinant VP1 expressed from $E$ coli as positive control (group C). Spleens were removed 2 weeks after final boost to make single-cell suspensions. Stimulated wells received purified VP1 at a final concentration of 10,5 , or $2.5 \mu \mathrm{g} / \mathrm{ml}$.

b POS was a composite of $\alpha-\mathrm{CD} 3$ and $\alpha-\mathrm{CD} 28$ and served as a positive mitogenic control. Values are from one representative experiment, and are presented as the mean \pm SEM for triplicate assays.

of $\alpha-\mathrm{CD} 3$ and $\alpha-\mathrm{CD} 28$, served as a positive mitogenic control. Mice given either transgenic tomato or bacterial VP1 protein developed a two- to three-fold better VP1-specific proliferative response than mice immunized with wild type untransformed tomato (Table 1). As lymphocytes can migrate from the spleen and circulate to mucosal tissues, where they proliferate and produce $\operatorname{IgA}$ against encountering antigens [27], results regarding splenocyte proliferation (Table 1) once again confirmed the development of VP1-specific memorial systemic splenocytes following oral antigen stimulation. Moreover, this result also suggested that edible vaccine can be as efficient as other vaccines delivered via intranasal or intramuscular route, which was considered as an effective method in generating mucosal and systemic immunity [13].

\subsection{Cytokine production profiles}

Profiles of cytokine released from VP1-stimulated spleen cells were examined to determine the primed pathway of immune responses. Cytokines IFN- $\gamma$, IL- 5 and TGF- $\beta$ were detected in the spleen cell supernatants (Fig. 5). Results showed none of the groups differed significantly in production of IL-5 (data not shown). However, mice fed transgenic tomato and VP1 protein from $E$. coli displayed a two to fivefold increase in IFN- $\gamma$ levels (Fig. 5A) and slight increase in TGF- $\beta$ levels (Fig. 5B) compared to those from mice fed wild-type tomato. IL-4, which is key cytokine for Th2, is usually very difficult to be detected due to rather low level and also is sticky to cell membrane and plates. Therefore, the author tried to assay the level of IL-4 with little success. The level of IL-10, another key factor for regulatory T cells, was not assayed since no significant suppressive activity was observed in this study. As the subsets of Th cells can be distinguished by the pattern of cytokines they produce [30], the results of cytokine profiles in this work suggested that Th1 and $\mathrm{Th} 3$ cells were involved in the production of VP1-specific antibody through oral immunization.
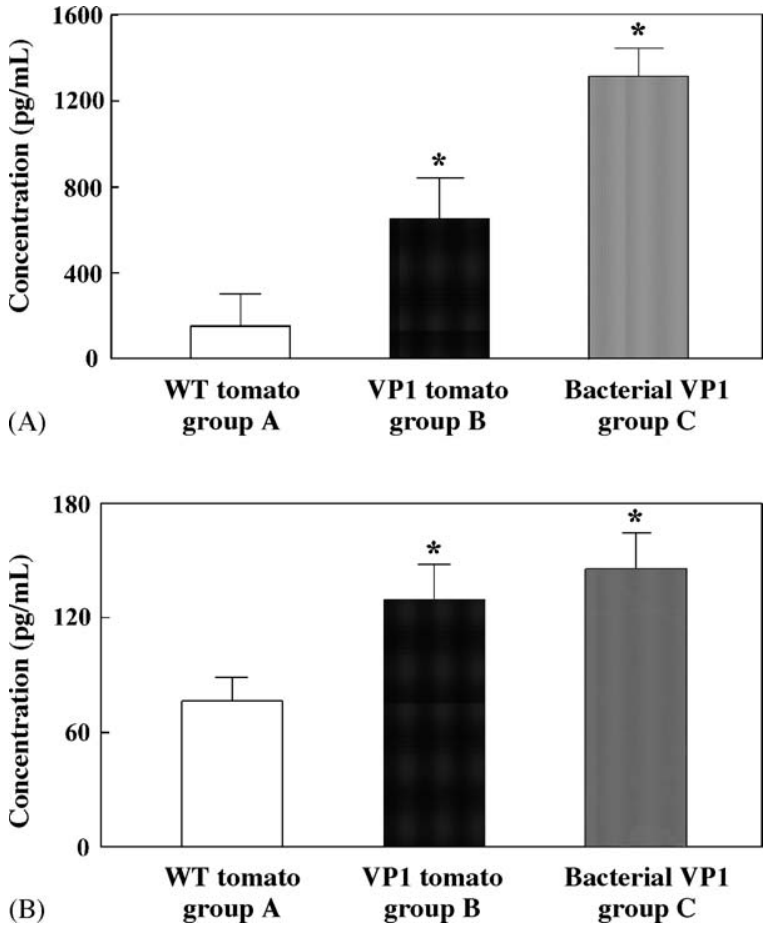

Fig. 5. Cytokine profiles of spleen cells stimulated with recombinant VP1 protein. Single-cell suspensions of spleen cells were stimulated with $5 \mu \mathrm{g} / \mathrm{ml}$ VP1 protein purified from E. coli. After 48 or $96 \mathrm{~h}$ in culture, cell-free supernatants were collected and assayed for the presence of (A) IFN- $\gamma$ and (B) TGF- $\beta$ cytokines using sandwich-ELISA. The value was presented as mean \pm SEM. Statistically significant values $(P<0.05)$ are indicated by an asterisk.

Th1 cells are known to produce IFN- $\gamma$ and IL-2, while Th2 cells produce IL-4 and IL-5, and Th3 cells produce mainly TGF- $\beta$; hence the identification of the cytokine profiles from spleen cells helps determine the route by which VP1-spicific antibodies were administered [30]. Also, development of the $\mathrm{CD}^{+}$Th cell subset is essential for eradicating infectious pathogens. Previous studies indicated expression of IgG2a in mucus as well as macrophage activation is the functional consequences of Th1 cells. Moreover, Th2 cells generally promote development of selected humoral immunity, including $\mathrm{IgG}$ expression [31]. Since exposure of the mucosa to virus antigen was previously hypothesized to induce Th2type responses [32], the data presented here surprisingly suggested that the immune responses of oral immunization were provoked through Th1- and Th3-type routes. Respiratory syncytial virus (RSV), a pathogen of infancy and early childhood, also displayed a Th1-type response both to its infection and to plant-derived oral vaccination [33], indicating antigen entering via mucus may also induce immunity via the Th1 route. Detection of IgG subtypes, including IgG1 and $\operatorname{IgG} 2 \mathrm{a}$, were done but disappointingly without significant difference among groups (data not shown). Therefore, further experiment is needed to clarify the processes involved in the future. 
Th3-type responses also tend to be involved in this study according to TGF- $\beta$ secretion. Th 3 cells are a subset of unique cells that produce mainly TGF- $\beta$ and develop principally in mucosal immune response to orally presented antigens. Although Th3 has been found to have the ability to induce IgA production and also suppress other immune responses, it is yet to be clarified on the interaction between the induction of mucosal immune response and suppressive effect. The data suggested the involvement of TGF- $\beta$ in the IgA antibody and mucosal immune response was induced in the mice fed transgenic tomato. It will be very interesting to find out if TGF- $\beta$ secretion could suppress the immune response induced by transgenic tomato. However, more studies are needed to clarify the role of TGF- $\beta$ in the regulation of mucosal immunity or tolerance. Since mucus is the first barrier against pathogens infection, including enterovirus, mucosal antibody remains more effective than humoral immune response in providing protection from virus invading [27].

Plants can be grown in large quantities easily and cheaply, and transgenic tomato fruit expressing VP1 protein was used as an oral vaccine in this study. With the benefits of increased safety, plant-derived vaccine remains an appropriate method for producing subunit vaccine [34]. The idea of oral vaccination combined with VP1 antigen deserves further research to create an alternative control measure for EV71, which continues to be one of the most serious seasonal epidemics, with significant mortality throughout the Asia-Pacific region.

\section{References}

[1] Mason HS, Warzecha H, Mor T, Arntzen CJ. Edible plant vaccines: applications for prophylactic and therapeutic molecular medicine. Trends Mol Med 2002;8:324-9.

[2] Kong Q, Richter L, Yang YF, Arntzen CJ, Mason HS, Thanavala Y. Oral immunization with hepatitis B surface antigen expressed in transgenic plants. Proc Natl Acad Sci USA 2001;98:11539-44.

[3] Haq TA, Mason HS, Clements JD, Arntzen CJ. Oral immunization with a recombinant bacterial antigen produced in transgenic plants. Science 1995;268:714-6.

[4] Kapusta J, Modelska A, Figlerowicz M, Pniewski T, Letellier M, Lisowa $\mathrm{O}$, et al. A plant-derived edible vaccine against hepatitis $\mathrm{B}$ virus. FASEB J 1999;13:1796-9.

[5] Lauterslager TG, Florack DE, van der Wal T, Molthoff JJ, Langeveld WJP, Bosch D, et al. Oral immunisation of naive and primed animals with transgenic potato tubers expressing LT-B. Vaccine 2001;19:2749-55.

[6] Lavelle EC, Grant G, Pusztai A, Pfuller O'Hagan UDT. Mucosal immunogenicity of plant lectins in mice. Immunology 2000;99:30-7.

[7] Warzecha H, Mason HS, Lane C, Tryggvesson A, Rybicki E, Williamson $\mathrm{AL}$, et al. Oral immunogenicity of human papillomavirus-like particles expressed in potato. J Virol 2003;77:8702-11.

[8] Shih SR, Ho MS, Lin KH, Wu SL, Chen YT, Wu CN, et al. Genetic analysis of enterovirus 71 isolated from fatal and non-fatal cases of hand, foot and mouth disease during an epidemic in Taiwandkjdot. Virus Res 2000;68:127-36.

[9] Lin TY, Chang LY, Hsia SH, Huang YC, Chiu CH, Hsueh C, et al. The 1998 enterovirus 71 outbreak in Taiwan: pathogenesis and management. Clin Infect Dis 2002;34:S52-7.
[10] Shih SR, Li YS, Chiou CC, Suen PC, Lin TY, Chang LY, et al. Expression of capsid protein VP1 for use as antigen for the diagnosis of enterovirus 71 infection. J Med Virol 2000;61:228-34.

[11] Yu CK, Chen CC, Chen CL, Wang JR, Liu CC, Yan JJ, et al. Neutralizing antibody provided protection against enterovirus type 71 lethal challenges in neonatal mice. J Biomed Sci 2000;7: 523-8.

[12] Henke A, Zell R, Stelzner A. DNA vaccine-mediated immune responses in Coxsackie virus B3-infected mice. Antiviral Res 2001;49:49-54.

[13] Wu CN, Lin YC, Fann C, Liao NS, Shih SR, Ho MS. Protection against lethal enterovirus 71 infection in newborn mice by passive immunization with subunit VP1 vaccines and inactivated virus. Vaccine 2002;20:895-904.

[14] Carrillo C, Wigdorovitz A, Oliveros JC, Zamorano PI, Sadir AM, Gomez N, et al. Protective immune response to foot-and-mouth disease virus with VP1 expressed in transgenic plants. J Virol 1998;72:1688-90.

[15] Chargelegue D, Obregon P, Drake PM. Transgenic plants for vaccine production: expectations and limitations. Trends Plant Sci 2001;6:495-6.

[16] Giddings G, Allison G, Brooks D, Carter A. Transgenic plants as factories for biopharmaceuticals. Nat Biotechnol 2000;18:1151-5.

[17] Arakawa T, Chong DK, Langridge WH. Efficacy of a food plant-based oral cholera toxin B subunit vaccine. Nat Biotechnol 1998;16:292-7.

[18] Mason HS, Haq TA, Clements JD, Arntzen CJ. Edible vaccine protects mice against Escherichia coli heat-labile enterotoxin (LT): potatoes expressing a synthetic LT-B gene. Vaccine 1998;16:1336-43.

[19] Richter LJ, Thanavala Y, Arntzen CJ, Mason HS. Production of hepatitis B surface antigen in transgenic plants for oral immunization. Nat Biotechnol 2000;18:1167-71.

[20] Bednarek SY, Wilkins TA, Dombrowski JE, Raikhel NV. A carboxylterminal propeptide is necessary for proper sorting of barley lectin to vacuoles of tobacco. Plant Cell 1990;2:1145-55.

[21] Neuhaus JM, Rogers JC. Sorting of proteins to vacuoles in plant cells. Plant Mol Biol 1998;38:127-44.

[22] Jeng ST, Yen CY. Effects of Rho-independent terminators on the expression of a plant gene. Physiol Plant 2000;108:171-9.

[23] Jobling SA, Gehrke L. Enhanced translation of chimaeric messenger RNAs containing a plant viral untranslated leader sequence. Nature 1987;325:622-5.

[24] Matsuoka K, Nakamura K. Propeptide of a precursor to a plant vacuolar protein required for vacuolar targeting. Proc Natl Acad Sci USA 1991;88:834-8.

[25] Bradford MM. A rapid and sensitive method for the quantisation of microgram quantities of protein utilizing the principle of protein dye binding. Anal Biochem 1976;72:248-54.

[26] Herman EM, Taqul BW, Hoffman LM, Kjemtrup SE, Chrispeels MJ. Retention of phytohemagglutinin with carboxyterminal tetrapeptide KDEL in the nuclear envelope and the endoplasmic reticulum. Plantation 1990;182:305-12.

[27] Coffin SE, Clark SL, Bos NA, Brubaker JO, Offit PA. Migration of antigen-presenting $\mathrm{B}$ cells from peripheral to mucosal lymphoid tissues may induce intestinal antigen-specific IgA following parenteral immunization. J Immunol 1999;163:3064-70.

[28] Walmsley AM, Kirk DD, Mason HS. Passive immunization of mice pups through oral immunization of dams with a plant-derived vaccine. Immunol Lett 2003;86:71-6.

[29] Zhang MJ, Wang MX, Jiang SZ, Xiu ZZ, Ma WY. Preparation and characterization of the monoclonal antibodies against Japanese encephalitis virus. Acta Virol 1992;36:533-40.

[30] Amemiya KG, Bush V, DeShazer D, Waag DM. Nonviable Burkholderia mallei induces a mixed Th1- and Th2-like cytokine response in BALB/c mice. Infect Immun 2002;70:2319-25.

[31] Abbas AK, Murphy KM, Sher A. Functional diversity of helper T lymphocytes. Nature 1996;383:787-93. 
[32] Street NE, Mosmann TR. Functional diversity of T-lymphocytes due to secretion of different cytokine patterns. FASEB J 1991;5: $171-7$.

[33] Sandhu JS, Krasnyanski SF, Domier LL, Korban SS, Osadjan MD, Buetow DE. Oral immunization of mice with transgenic tomato fruit expressing respiratory syncytial virus-F protein induces a systemic immune response. Transgenic Res 2000;9:127-35.

[34] Sala F, Rigano MM, Barbante A, Basso B, Walmsley AM, Castiglione $\mathrm{S}$. Vaccine antigen production in transgenic plants: strategies, gene constructs and perspectives. Vaccine 2003;21:803-8. 